\title{
Emociones ante un continente en ruinas: la Europa posbélica de Manuel Mujica Lainez en la crónica de viajes latinoamericana
}

Resumen: Desde la premisa de que el discurso sobre Europa es global, dinámico y multidireccional, este artículo propone analizar la mirada transatlántica de Manuel Mujica Lainez (1910-1984) y las emociones que suscita el continente en el célebre escritor y periodista argentino. El examen de las crónicas redactadas durante los tres viajes de 1945, 1948 y 1958 permitirá determinar así la sujeción de las emociones a normas ético-morales y contextos histórico-culturales determinados e identificar, además, un desarrollo en los enunciados emocionales que corre paralelo a un cambio perceptivo que, partiendo de la Europa en ruinas en la inmediata posguerra, conduce a la Europa eterna, en cuanto modelo cultural atemporal, en los años cincuenta.

Palabras clave: discurso sobre Europa, América Latina, Manuel Mujica Lainez, literatura de viajes, emoción

De acuerdo con una encuesta reciente del Eurobarómetro, la esperanza, la duda y la confianza son las tres emociones que más se asocian con la Unión Europea (cf. Flash Eurobarometer 2019: 4). Protestas climáticas, la crisis migratoria, el auge de diferentes movimientos populistas o el Brexit parecen haber logrado colmar o, por lo menos, aminorar el vacío emocional de los ciudadanos europeos ante la comunidad política; un vacío emocional lamentado aún pocos años antes desde posiciones, como las del filósofo alemán Detmar Doering y de la política Silvana Koch-Mehrin (cf. Doering / Koch-Mehrin 2009: 11), que consideran el compromiso afectivo del ciudadano indispensable para "the long-term success of European integration” (Gerner 2012: 652). A diferencia de la deplorada indiferencia popular, las tomas de posición públicas por parte de la clase política e intelectual en y frente a determinados contextos político-históricos apenas pueden pensarse exentas de emociones. También el nexo entre emoción y Europa dista de ser, en estos entornos, un fenómeno nuevo, pese a que el emotional turn en el estudio de las relaciones internacionales, es decir, la atención académica por dichas emociones sea de fecha reciente (cf. Clément / Sangar 2018: 3-4).

Mirjam Leuzinger, Universität Passau 
¿Es la emoción un requisito indispensable para la cohesión y, de ahí, la existencia de la comunidad europea? 0, por el contrario, ¿son las emociones responsables de los conflictos entre las naciones del continente? Recién terminada la Segunda Guerra Mundial, estos interrogantes contrapuestos subyacían en el debate sobre Europa que se impulsó en los primeros Rencontres Internationales de Genève, celebrados en setiembre de 1946. Con el recuerdo de la propaganda nazi y su poder emotivo de crear "consent and social conformity" (Sanchez Salgado 2018: 103) aún en mente, el intelectual francés Julien Benda se posicionaba, por una parte, decididamente contra las emociones que refuerzan el nacionalismo. Al pathos del nacionalismo, Benda prefiere contraponer la razón y el carácter universal de las ciencias como fundamentos de la Europa futura (cf. Benda et al. 1947: 28). Por otra parte, su contrincante, el poeta británico Stephen Spender, responsabiliza a la investigación científica del desarrollo de armas de destrucción masiva que tuvo lugar y que se aplicó durante la guerra. En oposición a la nefasta insensibilidad atribuida a la técnica, las emociones se convierten, para Spender, en una vía de conocimiento imprescindible para percibir el sufrimiento humano y solidarizarse con él (cf. Spender en: Benda et al. 1947: 169).

Al margen de la tradicional polaridad entre emoción y razón (cf. Bartra 2012: 17) que aquí se vislumbra, la controversia entre Benda y Spender ejemplifica el vínculo histórico entre el fenómeno de la emoción y el discurso intelectual sobre Europa que se pronuncia al término de la Segunda Guerra Mundial. Conforme ha dejado constancia Susanne Klengel al analizar los textos autobiográficos de los brasileños Sérgio Milliet, Alceu Amoroso Lima y Paulo Duarte, del peruano Ventura García Calderón, de la argentina Victoria Ocampo y de los mexicanos Jaime Torres Bodet, Octavio Paz y Silvio Zavala (cf. Klengel 2011: 33-45), también los intelectuales latinoamericanos residentes o de paso en Europa -o sea, migrantes o viajeros- se sumaron al discurso en ese momento particularmente delicado y decisivo para la futura unidad continental. Lejos de ser una preocupación exclusivamente europea, el viejo continente puede pensarse, por lo tanto, en términos de un discurso global dinámico, múltiple y multidireccional, al cual la élite intelectual latinoamericana añade una mirada afectiva diversa y diferenciada.

Con el fin de esbozar esta mirada transatlántica, ${ }^{1}$ el presente estudio propone examinar, a modo de ejemplo, las emociones que suscita el continente en Manuel

1 Este propósito sigue el enfoque transatlántico propuesto para el proyecto de habilitación "Entre identidad y alteridad: el discurso sobre Europa en la ensayística de América Latina y Francia (1945-1992)" que la autora lleva a cabo en la Universität Passau. 
Mujica Lainez (1910-1984), escritor y periodista consagrado y celebrado en su Argentina natal (cf. Cruz 1982: 74, 95; Victory 2017: 342). En concreto, se tomarán en cuenta las crónicas redactadas durante los tres viajes de 1945, 1948 y 1958, y reunidas en el primer tomo de Placeres y fatigas de los viajes: Crónicas andariegas (1983), así como en la antología El arte de viajar (2007), editada por Alejandra Laera. $^{2}$ Estos tres viajes son de interés particular porque se trata de las únicas estancias posbélicas de Mujica Lainez en Europa financiadas por el diario La Nación (cf. Larea 2007: 15) y, sobre todo, porque revelan una transformación singular y significativa en la imagen que el autor brinda de sí mismo; un antes y un después que Laera clasifica "[del] cronista en tiempos turbulentos [... al] viajero de tierras inmemoriales" (Laera 2007: 36-37). ${ }^{3}$ La tesis que aquí se plantea es que estos tres momentos clave -1945, 1948 y 1958- evidencian asimismo un desarrollo en los enunciados emocionales que corre paralelo no solo a la mencionada transformación en la imagen del autor, sino también a la percepción cambiante de Mujica Lainez de una Europa en ruinas en la inmediata posguerra a una Europa eterna, en cuanto modelo cultural atemporal, en los años cincuenta.

\section{Manuel Mujica Lainez, el cronista y el viajero en su contexto}

Según resalta el biógrafo Jorge Cruz, la obra literaria de Manuel Mujica Lainez suele dividirse en dos ciclos: por un lado, la llamada "saga argentina", una serie de prosas sobre la capital argentina que se inicia con la opera prima Don Galaz de Buenos Aires (1938) y encuentra su máxima expresión en la colección de cuentos Misteriosa Buenos Aires (1951) y, por otro, las novelas históricas de contenido europeo o universal, como la obra cumbre Bomarzo (1962), con las

2 En el primer tomo de Placeres y fatigas de los viajes, Mujica Lainez - “ya consagrado, libre de la instancia periodística y en el umbral del fin de su carrera" (Laera 2007: 13)- reúne una selección personal de crónicas, publicadas anteriormente en y/o redactadas para el diario argentino La Nación (cf. Mujica Lainez 1984: 8; Laera 2007: 357-364). Para la antología de 2007, Laera retoma "un conjunto significativo" de estos textos, complementándolo con "casi todas las crónicas inéditas en libro" que ha logrado rescatar de la hemeroteca del Congreso de la Nación (cf. Laera 2007: 37-38).

3 Además de los viajes posbélicos seleccionados, Mujica Lainez se traslada a Europa en 1935, 1960, 1974 y 1977, así como en 1979, 1980 y 1982, aunque de estos tres últimos periplos no haya dejado constancia en sus crónicas (cf. Cruz 1996: 198). 
cuales el escritor afianza definitivamente su fama de buen narrador (cf. Cruz 1996: 24; Vázquez 1983: 194-195; Villena 1976: 13-14). ${ }^{4}$

Ante la abundante labor literaria, no es de olvidar, sin embargo, que Mujica Lainez -proveniente de "una familia [...] con cierta tradición en las letras y el periodismo" (Villena 1976: 12) ${ }^{5}$ trabajaba desde 1932 y durante más de cuatro décadas como redactor de crónicas para el prestigioso diario argentino $\mathrm{La} \mathrm{Na}$ ción (cf. Cruz 1996: 88). En dicha función, el diario le envía reiteradas veces al extranjero, como cuando viaja en el Graf Zeppelin a Alemania en 1935 o, cinco años más tarde, acompaña a políticos en una misión económica al Japón (cf. Cruz 1996: 11-12). A este respecto, cabe destacar que, cuando Mujica Lainez entra, por invitación del fundador Adolfo Mitre, a formar parte del cuerpo de redactores, el periódico se hallaba en "la plenitud de su prestigio" (Cruz 1996: 89; cf. asimismo Villena 1976: 13). También el género de la crónica -de larga y respetada tradición en dicho medio, gracias a la colaboración de personalidades latinoamericanas tan ilustres como José Martí o Rubén Darío- gozaba de extensos círculos lectores (cf. Laera 2007: 29).

Pese al prestigio y a la considerable difusión del diario y del género, las crónicas de Mujica Lainez -escritas y/o publicadas entre 1935 y 1977- no han suscitado, empero, mucho interés en la crítica especializada, a excepción del estudio introductorio a la edición de Laera (2007), así como de un capítulo en la monografía de Julio Peñate Rivero (2012), dedicada al relato de viaje hispánico. Por lo visto, no se ha examinado aun suficientemente la relevancia de la labor cronística de Mujica Lainez tanto para "darse a conocer" como para "afianzar su vocación" de escritor (Laera 2007: 14). Tampoco se ha reparado en la inscripción de una parte de las fuentes en la larga tradición latinoamericana, en general, y argentina, en particular, que otorga al llamado "viaje a Europa” un carácter consagratorio (cf. Jitrik 1969: 12; Pagni 2010: 43). Para el objetivo del presente estudio, conviene resaltar igualmente la excepcionalidad de un testimonio ocular, "imprescindible" para los lectores del diario La Nación para entender o, por lo menos, apreciar la actualidad política de la Europa posbélica (Laera 2007: 31). Dicho en otras pala-

\footnotetext{
4 Pese a la fama de sus novelas, conviene resaltar que la vasta obra de Mujica Lainez comprende asimismo un libro en alejandrinos, así como poemas y cuentos, tres biografías y numerosos textos periodísticos. Un repaso de su obra ofrece Cruz 1982.

5 Entre los antepasados de la línea materna se encuentran el periodista Florencio Varela, el antiguo ministro de Hacienda y redactor en jefe de La Tribuna Rufino J. Varela, así como Manuel Lainez, quien fundó y dirigió El Diario. Pese a la ilustre genealogía -en la cual destaca, por vía paterna, asimismo el conquistador Juan de Garay-, Mujica Lainez pertenece "a una generación de nietos, a la que le tocó nacer y experimentar el crepúsculo de las elites tradicionales a las que pertenecían” (Victory 2017: 343). Para más detalle, cf. Cruz 1996: 26-34.
} 
bras, ha de tomarse en cuenta que los relatos son el resultado de una experiencia viajera previa, es decir, que Mujica Lainez experimentó en carne propia el continente en ruinas y contempló personalmente los desafíos tanto arquitectónicos como sociales, culturales y éticos de su reconstrucción.

Del primer viaje de casi tres meses, el autor deja constancia "con una frecuencia por momentos diaria en la primera o la segunda página del diario" (Laera 2007: 19). El resultado son dieciséis crónicas - de una extensión, por lo general, de entre cuatro y cinco páginas-, escritas entre el 23 de setiembre y el 10 de diciembre de 1945 y reeditadas en el volumen de 1983, además de ocho textos rescatados por Laera en su antología de 2007. Enviado por el diario La Nación y por invitación de "los ingleses" (Vázquez 1983: 66), Mujica Lainez (junto con otros profesionales argentinos) viaja, primero, a Londres y a la zona de ocupación británica de Alemania, desde la cual remite -con nueve páginas- las únicas crónicas más largas del conjunto de 1945. Después, visita París y algunas ciudades del norte y del este de Francia. Con el permiso expreso del diario, el cronista añade, finalmente, una estancia de quince días en Estocolmo, donde asiste a la ceremonia de los Premios Nobel, en la cual se galardonó a la primera escritora latinoamericana y primera mujer, la chilena Gabriela Mistral, una conocida del autor Victoria Ocampo mediante (cf. Vázquez 1983: 69-70). Del segundo viaje quedan reeditadas solo siete crónicas con una extensión comparable a las anteriores y con fechas entre el 3 y el 23 de junio de 1948: cinco por el propio Mujica Lainez y dos adicionales por Laera. En este corto período, Mujica Lainez -cuyo apoyo a los Aliados era conocido (cf. Cruz 1996: 97) - vuelve a Reino Unido y visita, “con una delegación periodística” (Cruz 1996: 12), las ciudades de Birmingham, Glasgow, Edimburgo y Londres.

El viaje más largo y con treinta y cuatro crónicas, seleccionadas todas para la antología de 1983, también el más documentado es, finalmente, el tercer viaje a Europa, iniciado a principios de enero de 1958 y finalizado a mitad de julio del mismo año. En él, Mujica Lainez recorre distintas ciudades españolas y francesas para volver a Londres, desde donde navega a la parte continental de Grecia, así como a algunas de las islas. A una breve etapa en la República Popular Rumana -fundada oficialmente en 1947, pero bajo influencia soviética desde el término de la Conferencia de Yalta de 1945 (cf. Du Réau 2001: 135)- le siguen, por último, unos días en Italia, donde visita por primera vez Bomarzo, municipio que dará el título a su novela cumbre de 1962 (cf. Cruz 1982: 83; Cruz 1996: 13). Aunque en las propias crónicas apenas se documente, la situación profesional de Mujica Lainez había cambiado sensiblemente en el lapso de tiempo entre 1948 y 1958. Tras la Revolución Libertadora de 1955, el autor -antiperonista- había asumido el cargo de "Director General de Relaciones Culturales del Ministerio de Rela- 
ciones Exteriores” (Laera 2007: 24). ${ }^{6}$ Además, en 1956, Mujica Lainez había sido elegido miembro de la Academia Argentina de las Letras. El tercer periplo al continente europeo lo emprende, por consiguiente, como funcionario y, más aún, como “embajador cultural de la Argentina” (Laera 2007: 24), un renombre que se confirma también en la extensión mayor de los textos que ronda ahora, a menudo, los seis a once folios.

\section{La Europa en ruinas, entre información y emoción}

En el prólogo al primer volumen de Placeres y fatigas de los viajes, Mujica Lainez ofrece una definición del viaje que desatiende, a primera vista, las emociones: para él, viajar es, antes que nada, aprender (cf. Mujica Lainez 1984: 7). ${ }^{7}$ Consecuentemente, el autor se describe como testigo privilegiado y selecto que anota y ordena “observaciones” (PF: 48), que ve “aquí y allá”, tratando “de demostrar” lo expuesto (PF: 53), o que intenta, con “afán de informante” (PF: 88), "apreciar en toda su hondura" la realidad europea (PF: 141). En ocasiones, abandona la primera persona y se refugia en la tercera, llamándose a sí mismo “periodista” (PF: 42, 44, 108, 142; Mujica Lainez 2007: 143), "autor” (AV: 208) o -sobre todo en las crónicas de 1958- "viajero" (cf., entre otros ejemplos, PF: 120, 180, 252, 337; AV: 127, 173). Tal descripción de sí mismo revela una manera de proceder estructurada y racional, por instantes hasta distanciada, la cual deja relacionarse, en definitiva, con la función de periodista que Mujica Lainez resalta de su persona tanto en los textos de 1945 como en aquellos de 1948.

Al mismo tiempo, la propia presencia del sujeto observador, que en los ejemplos dados se vislumbra, distingue la crónica de viaje de un texto meramente informativo. Subrayando este rasgo distintivo, el crítico argentino Noé Jitrik observa, para la crónica de viaje a Europa, un desplazamiento de "la voluntad de informar" hacia el "informar otra vez, y como siempre, de sí a propósito de la información” (Jitrik 1969: 14). También Peñate Rivero resalta, en

\footnotetext{
6 A este cargo, Mujica Lainez renunciará, sin embargo, con la llegada al poder de Arturo Frondizi en mayo de 1958, es decir, antes de terminar el tercer viaje (cf. Cruz 1996: 12-13). Lamentablemente no se ha podido encontrar información relativa a la repercusión de esta renuncia sobre la financiación y el recorrido del viaje.

7 En lo sucesivo, las referencias a las crónicas reunidas en el primer tomo de Placeres y fatigas de los viajes: Crónicas andariegas se indicarán mediante la abreviatura PF.

8 En lo sucesivo, las referencias a las crónicas editadas en El arte de viajar. Antología de crónicas periodísticas (1935-1977) se indicarán mediante la abreviatura AV.
} 
relación con el género viático, el "equilibrio inestable” entre el sujeto y el "objeto observado” (Peñate Rivero 2004: 19). Independientemente de las proporciones de dicho equilibrio, la presencia textual del sujeto puede dar cabida, por consiguiente, a la descripción del "impacto del viaje" experimentado, de las "sensaciones" vividas y de la "visión del mundo" del viajero: tres rasgos del esquema analítico establecido por Peñate Rivero en las que las emociones parecen discernirse preferentemente. ${ }^{9}$ En mayor o menor medida, las emociones se inscriben, en suma, en el relato del viajero.

Por ser quien brinda la información sobre su entorno, el viajero puede entenderse, en palabras de la antropóloga Maruška Svašek, como un "relational being-in-the-world", atraído emocionalmente por "his or her surroundings" (Svašek 2012: 3). De esta suerte es como también el cronista Mujica Lainez discierne su entorno y traza las emociones causadas por este. En efecto, el autor expresa su emoción al volver a ver la Catedral de Nuestra Señora en París, tal y como la admiraba cuando a los trece años se trasladó con su familia a la capital francesa (cf. PF: 88). ${ }^{10}$

A la par, el autor -que había residido en París entre 1923 y 1925 y redactado ahí su primera novela en francés, inédita hasta la fecha (cf. Cruz 1996: 11, 62)sufre por las discrepancias entre sus recuerdos y la visión que se le presenta en 1945:

El viajero que recorre actualmente Europa y que había andado antes por aquí, tiene la impresión angustiosa de que alguien ha entrado con una tijera cruel en su álbum de viejas fotografías. (AV: 173)

9 El esquema de análisis de Peñate Rivero se divide en cuatro planos que toman en consideración 1) la diégesis, 2) la estructura, 3) la expresión y 4) la significación. El impacto del viaje señalado pertenece al primer plano en el cual se examinan, asimismo, el desplazamiento, la finalidad del viaje, los actores, los medios de transporte, las fuentes de información y la presencia del otro. El segundo rasgo destacado, a saber, las sensaciones, forma parte de la subcategoría “descripción y digresión” y, a nivel de los planos, de la estructura que contempla, igualmente, el "viaje como elemento movilizador", el narrador, la historia, la interlocución, el ritmo discursivo, el molde genérico y los materiales introducidos en el relato. El último aspecto referido, la visión del mundo, se analiza -junto con el destinatario, la recepción, el interés del texto y la configuración interdiscursiva- en el plano de la significación (cf. Peñate Rivero 2012: 22-23; para una primera versión del esquema, cf. también Peñate Rivero 2004: 26-28).

10 Según Mujica Lainez, los motivos de este traslado eran, por un lado, el deseo de sus padres de brindarles a él y a su hermano menor Roberto una buena formación cultural y, por otro, de carácter económico, puesto que en la época “era más barato vivir en París que en Buenos Aires" (Vázquez 1983: 16). 
También en su visita a Ruan, la capital de Normandía, Mujica Lainez insiste en la impresión de que "parte de [su] álbum juvenil se [le] escapaba de entre las manos, cerrado para siempre" (AV: 187). La angustia, que recogen las citas, ilustra, por lo tanto, que emocionarse no solo es un "context-dependent process” (Boccagni / Baldassar 2015: 75), sino también una reacción provocada por la memoria del sujeto (cf. Svašek 2012: 3, 12). Así, por ejemplo, el escritor dice emocionarse asimismo al ver el puerto flotante de los británicos en la costa francesa (cf. PF: 101), pues tras la estancia en París había residido ocho meses en Londres y afianzado ahí su predilección por el pueblo británico que salpica las páginas del libro. ${ }^{11}$

Al respecto, conviene tomar en cuenta que Francia e Inglaterra eran "para la clase tradicional argentina, sobre todo en las primeras décadas de este siglo [XX], un paradigma de civilización y buen tono" (Cruz 1996: 70). En los términos críticos de César Aira, estos países conforman "un escenario de la fantasía ya creado" (Aira 1993: 74), un objet trouvé literario o un ready-made (cf. Aira 1993: 74, 76) que pierde, con su presencia reiterada en diversos textos, el impulso innovador. Su carácter predeterminado afecta, entonces, también la visión emocional de las dos naciones, la cual enlaza -tanto en lo tocante a su vertiente social como literaria- con un "normative discourse", reforzado por "learned and internalised attitudes and preferences” (Svašek 2012: 12). En cuanto manifestaciones culturales, las emociones están regidas, a fin de cuentas, por feeling rules implícitas (cf. Hochschild 1979: 563) que determinan -adecuándose, por lo general, a posibles reacciones de terceros- lo que debe sentirse y cómo uno cree que tiene el derecho o el deber de manifestar sus emociones en un contexto históricocultural determinado (cf. Hochschild 1979: 564; Stets / Trettevik 2014: 33-34).

Amén de resaltar la importancia del contexto, de la memoria y del carácter normativo de las emociones, los ejemplos referidos de Francia e Inglaterra evidencian el sentido positivo que cobran el nombre genérico emoción y el verbo correspondiente emocionarse. Este hecho no es baladí en vista de la connotación mayormente negativa que tienen las emociones concretas o, dicho de otro modo, los emotives o enunciados emocionales (cf. Reddy 1999: 267) que Mujica Lainez formula en sus relatos. La lista de emociones negativas, localizadas todas ellas en las crónicas de 1945, es considerable y engloba, verbigracia, la "angustia” (PF: 78; AV: 189), el “ansia” (PF: 105), la “confusión” (AV: 153), el “desconcierto” (AV: 123) y el "desconsuelo" (PF: 76), el “estremecimiento” (PF: 96, 100) y el "furor”

11 De los ocho meses en Inglaterra, donde reside en casa de unos tíos y le instruye un tutor privado, Mujica Lainez no cuenta, sin embargo, casi nada en sus escritos (cf. Vázquez 1983: 22; Laera 2007: 15). 
(PF: 39), la "humillación” (PF: 70), la “melancolía” (PF: 98), el "odio" (PF: 84, 105) y el "rencor" (PF: 84), la "resignación” (PF: 62), la "soledad” (PF: 66), el “sufrimiento" (PF: 39) y la “tristeza” (PF: 66).

Tanto la gran variedad de ejemplos como la presencia simultánea de los polos negativo-positivo permiten llamar la atención sobre las "discontinuities" emocionales (Boccagni / Baldassar 2015: 73) que cualquier viaje provoca y que -tenida cuenta del género viático- parecen derivar, en gran medida, de la alteración constante en la "relación entre exterioridad (lo visto) e interioridad" (Peñate Rivero 2004: 27) y del carácter transitorio del propio viaje que conlleva siempre una vuelta al punto de partida geográfico. De este modo, la felicidad al volver a descubrir los lugares de la infancia, es decir, la felicidad provocada por la memoria puede chocar violentamente -y acaso apenas unas líneas más tarde- con las reacciones emocionales al confrontarse con la Europa en ruinas del presente. A diferencia de la migración, en cuyo contexto se ha puesto de relieve la "transformation of emotional life" (Boccagni / Baldassar 2015: 74), las emociones que el viajero dice experimentar a lo largo de su recorrido se manifiestan, en resumen, de manera más breve y pasajera.

Ahora bien, las emociones no solo se tematizan explícitamente al hilo de las crónicas. Las mismas se evidencian también a nivel de la expresión, a saber, a través de una serie de recursos estilísticos que conforman lo que podría llamarse una retórica de la emoción. En sintonía con la retórica aristotélica, los afectos así expresados encierran un poder de persuasión que se confirma mediante la reacción emocional de los oyentes (cf. Geisenhanslüke 2018: 103). ${ }^{12}$ Para las crónicas seleccionadas puede deducirse, por lo tanto, el rol capital de los lectores a la hora de descifrar, de calificar o de clasificar las emociones. En otras palabras, las emociones se construyen -no exclusivamente, pero sí también- mediante el diálogo entre la voz narrativa y los lectores, sean estos reales o implícitos.

$\mathrm{Al}$ examinar las formas de cómo se transmiten las emociones experimentadas a los lectores implícitos, en los cuales se fundamenta la presente reflexión, se ha podido observar, en las crónicas de 1945, un recurso continuado a campos léxicos connotados negativamente, a adjetivos valorativos y superlativos, a metáforas y exclamaciones, a la personificación de Europa, así como a la primera persona del plural. Referente a los campos léxicos, la Europa posbélica se describe, de este modo, a través de una isotopía de la destrucción, de la muerte y del sufrimiento que crea un ambiente con un alto potencial emotivo.

12 En cuanto al alcance de los afectos y las emociones para Aristóteles, cf. Geisenhanslüke 2018: 103-106. 
En palabras de Mujica Lainez y haciendo referencia a Los desastres de la guerra (1810-1815) - la famosa serie de grabados que Goya realizó en torno a la guerra de la Independencia española- sus observaciones conforman una "goyesca colección contemporánea de 'horrores de la guerra”” (AV: 187). En otra ocasión, el autor resume estos horrores con la expresión "clima guerrero", la cual define como emoción per se (PF: 54). Al parecer, la locución insiste en el causante de las emociones (i. e. la guerra) para aludir metonímicamente a los sentimientos resultantes. Le sirve al autor, por ende, para compendiar una serie de emociones diferenciadas, pero confluyentes en el contexto de 1945.

Como se ha anticipado, este clima se acentúa, igualmente, mediante una marcada adjetivación y el uso de superlativos, incluyendo, en orden alfabético y entre otros términos calificativos, lo apocalíptico (cf. PF: 56), arrasado (cf. PF: 64) y atroz (cf. PF: 40, 76), lo crudo (cf. PF: 53), destrozado (cf. PF: 64) y devastado (cf. PF: 45), lo difícil (cf. PF: 57), doloroso (cf. PF: 105) y espantoso (cf. PF: 53, 75), lo feroz (cf. PF: 64), gravísimo (cf. PF: 40), muerto (cf. PF: 76) y satánico (cf. PF: 78), así como lo trágico (cf. PF: 39, 69; AV: 177, 188), triste (cf. PF: 45) y vertiginoso (cf. PF: 44). Con el objetivo de intensificar este clima, Mujica Lainez emplea, además, términos connotados negativamente y expresiones metafóricas como la "crueldad” (PF: 64), el "desastre” (PF: 97, 99) y el "sacrificio" (AV: 125), la "llaga viva" (PF: 100), la "herida en el alma" (PF: 114) o las "heridas cruentas" (AV: 186), la "lección terrible" (PF: 70) y la "muerte” (PF: 78), la “negra mirada” (PF: 40) o las "nubes negras" (PF: 114), las "ruinas” (PF: 68, 75) y las "necrópolis" (PF: 77) y, con referencia a las capitales de Inglaterra y Francia, las “cicatrices" que "tatúan el cuerpo" londinense (PF: 39) y las "lágrimas" de París (AV: 177).

De igual manera, a este clima contribuyen exclamaciones como "i[q]ué viaje macabro este que me toca realizar por la Europa de 1945!” (AV: 186) y -allende de las personificaciones de Londres y París que se anticipan en los dos ejemplos anteriores- la prosopopeya de la propia Europa. Para Mujica Lainez, se trata de una Europa que "gemía bajo la garra nazi" (AV: 144) y que -"pobre y hambrienta" (PF: 40), enferma y "exhausta” (AV: 135)- depende ahora de los alimentos que le podría suministrar su Argentina natal:

Si queremos que Europa sea en lo futuro algo más que un inmenso y triste museo arqueológico, ello depende en mucho de la inyección de "jugo de carne" criolla que infiltraremos en sus venas endurecidas antes de que sea tarde. (AV:137)

A juzgar por las palabras del autor, los roles tradicionales de Europa y de Argentina se han invertido, de modo que "[l]a posguerra aparece como la coyuntura privilegiada para que el 'Viejo Mundo' sea salvado por el Nuevo Mundo" (Laera 2007: 23). Las emociones subsumidas en la expresión "clima guerrero" 
afectan, por ende, también al discurso sobre la Europa que se vislumbra en las crónicas, pese a que en las mismas se percibe también cierta esperanza depositada en las futuras generaciones y en la persistencia del espíritu cultural de Europa (cf. PF: 70, 105, 125; AV: 156, 176). “[N]ada es hoy muy agradable en Europa” (PF: 64), resume Mujica Lainez las ruinas tanto materiales, como morales y sociales que percibe en su recorrido por París y Londres y, más aún, en Estrasburgo y la zona de ocupación británica con ciudades y regiones afectadas por los bombardeos como Herford y Hamburgo, la cuenca del Ruhr y Westfalia.

Dicho lo anterior, conviene reparar ahora el hecho de que, paradójicamente, la retórica de la emoción le permite a Mujica Lainez acallar, por lo menos en parte, las emociones concretas que siente ante los escombros de la guerra, al desplazarlas del mensaje en sí a los destinatarios del mismo. Los motivos de este silencio parcial pueden ser varios: tal vez, verbalizarlas sería expresar lo obvio; tal vez, reducirlas a un único término y a una única persona que las siente sería taxativo; quizás, la fuerza emotiva se perdería con un discurso demasiado analítico en lo que a las emociones se refiere. Allende de estas razones sugeridas, conviene fijarse asimismo en las propias crónicas, las cuales permiten poner de relieve, además, la presencia de un topos literario de larga tradición en el relato de situaciones extremas (cf. Siguan 2014: 44-45), a saber, el topos de lo indecible. Este pone en debate las insuficiencias de la lengua o sus dificultades a la hora de expresar lo vivido, debido, verbigracia, al miedo de caer en lugares comunes o de sofocar el interés de los lectores (cf. Siguan 2014: 47-48). En los relatos de Mujica Lainez, este topos se aprecia en tres ocasiones (cf. PF: 70, 75, 340). A título de ejemplo, puede citarse, pues, la exclamación del autor cuando visita el puerto de Hamburgo en octubre de 1945:

Infierno del hierro retorcido, del ladrillo pulverizado, del cemento reducido a escombros: eso es hoy el puerto de Hamburgo. Me faltan palabras para describir su desolación. (PF: 70)

Recurrir al lenguaje figurado, tal y como ocurre en la primera parte del enunciado, es un recurso típico del topos (cf. Siguan 2014: 49). Además, el asíndeton que le sigue a la metáfora del infierno intensifica y dramatiza lo dicho. Mujica Lainez se aproxima, por lo tanto, a la realidad atroz -de modo metonímico, describiendo la desintegración de tres materiales: el hierro, el ladrillo y el cemento-, sin detallar la desolación del paisaje y sin aludir a la desolación humana que la primera encierra. Al final, se resigna, optando por el silencio. En este caso, el silencio cobra, sin embargo, un sentido ético, puesto que, ante la insuficiencia de la lengua, invita a los lectores a colmar sus lagunas (cf. Siguan 2014: 47). En términos metafóricos, invita, en fin, a reconstruir las ruinas idiomáticas, sosias de las ruinas arquitectónicas e implícitamente humanas de la guerra que el puerto ejemplifica. 
Hasta qué punto la mirada de Mujica Lainez sobre Europa es emocional, se nota, en último lugar, en la imposibilidad de percibir la belleza del arte y, en general, de las bellas artes por encima del desastre de la guerra:

Pero si por un momento supuse que su contemplación [la contemplación del tapiz de la reina Matilde en Bayeux] me alejaría estéticamente de la impresión que la guerra actual produce, ¡cuánto me equivocaba! [...] ¿Es que el hombre no cambiará nunca? ¿Será siempre así? ¿Acaso no se insinúa ahora, sobre la Europa incendiada y desgarrada en mil jirones sangrientos, el viento cruel de las discordias, cuyo gemido no calla jamás? No quiero ni pensarlo. (PF: 102)

Sin duda, la exclamación “¡cuánto me equivocaba!”, las subsiguientes preguntas retóricas y el lenguaje figurativo forman parte de la retórica de la emoción antes examinada. Antes que nada, conviene repararse, sin embargo, en la sujeción del testimonio de 1945 a ciertas convenciones ético-morales o, en los términos antes referidos de la socióloga Arlie Russell Hochschild, a ciertas feeling rules (cf. Hochschild 1979: 563; Stets 2010: 265). Desde este punto de vista moral, digresiones sobre la belleza del arte o sobre el placer estético de una lectura o de un espectáculo parecerían inoportunas en medio de la destrucción y la muerte relatadas. A juzgar por el pasaje citado y los ejemplos siguientes, es muy probable que el propio Mujica Lainez haya sido consciente de ello: no solo cuida de vincular estos placeres con el contexto bélico al insistir, por ejemplo, en los destrozos en las catedrales y museos (cf. PF: 88, 109, 113-114). También se limita a interpretarlos como una prueba de "la lucha [...] por volver a ser lo que ha sido" (PF: 48), es decir, como una prueba de que Europa se encuentra en vías de recuperar la libertad de expresión y la democracia (cf. PF: 58; AV: 146) y, con ellas, su autoridad cultural. "El espíritu de Europa sigue allí intocado" (AV: 176), se alegra, de este modo, en su visita al Louvre. En resumidas cuentas, el placer estético no puede sino asociarse con la constatación, a menudo, solemne, del "triunfo del espíritu" de Europa sobre la barbarie de la Segunda Guerra Mundial (PF: 89, cf. también PF: 56, 97).

\section{La Europa eterna, entre placeres y fatigas}

Si bien los viajes de 1945 y de 1958 pueden entenderse, en términos generales, como dos momentos diferenciados en lo que al discurso emocional sobre Europa se refiere, el paso de la Europa en ruinas a la Europa eterna, que se determinará en lo sucesivo, es gradual. Ya en las últimas crónicas de 1945 pueden observarse pocos, pero significativos cambios en el tono de la voz narrativa. De este modo, en noviembre de 1945, Mujica Lainez empieza a hablar de sus 
“andanzas en Europa” (PF: 112; cf. también PF: 315-316, 329, 363), como si, mediante esta fórmula de modestia, su recorrido recuperara cierto carácter azaroso y despreocupado, reiterado a través de una mirada igualmente despreocupada sobre el objeto de su observación. Tanto la expresión de las andanzas que enlaza con las “crónicas andariegas” resaltadas en el subtítulo del volumen, como la despreocupación con cara al entorno se imponen, finalmente, en las crónicas de 1958.

Esta transformación fundamental ha sido resaltada, con anterioridad, por Laera: conforme señala la filóloga argentina, en las crónicas de 1958 ya "no hay aventuras ni conflictos", sino "descubrimientos, sorpresas; en fin, placeres" (Laera 2007: 25). A nivel de los contenidos, estos placeres se traducen en una “descontextualización” (Laera 2007: 32) respecto de la actualidad política y social. A diferencia de las crónicas de 1945, se deja de resaltar, por lo tanto, lo circunstancial de las experiencias. Mujica Lainez -antes “cronista” o "periodista" (PF: 42) que da testimonio de la situación internacional- se convierte en “viajero" (PF: 164, 252, 322; AV: 173) o, incluso, en “escritor viajero" en busca de nuevo material para sus novelas históricas (cf. Laera 2007: 12, 35). No solo su función de “embajador cultural” (Laera 2007: 24) y su celebridad anteriormente señaladas secundan el desplazamiento en el estatus del autor, sino también el momento y lugar de publicación: gracias a la consulta de los archivos de La Nación, Laera ha podido constatar, al respecto, un marcado desajuste entre las fechas de redacción y de publicación de las crónicas (cf. Laera 2007: 32), y se ha percatado de que las crónicas desaparecen de las primeras páginas del diario, dedicadas a la actualidad (cf. Laera 2007: 34-35).

Tal despreocupación de cara a la actualidad política y social afecta también al discurso sobre Europa. Así pues, el viejo continente recupera paulatinamente la posición -tradicional y conservadora- de referente civilizatorio. Es decir, reconquista su "paisaje sentimental" predeterminado (Jitrik 1969: 17) y su "armonía perfecta”, en sintonía con una actitud latinoamericana que Jitrik opta por llamar "enceguecedora en lo cultural” (Jitrik 1969: 16). A excepción de la Rumanía soviética de la que el conservador Mujica Lainez se distancia y se apiada, ${ }^{13}$

13 Movido muy probablemente por cierto afán de mostrar que su "empecinado conservadorismo" le ponía a salvo de cualquier "sospecha de un cambio fundamental en [sus] principios e ideas" (PF: 315), Mujica Lainez resalta, durante su estancia en Bucarest, la "sensación de pesar silencioso" y su "impresión de invencible tristeza" y de "depresión del ambiente" (PF: 317). En este sentido, la República Popular Rumana visitada no solo difiere de la Europa occidental, sino también de un pasado nacional en el cual los rumanos, en cuanto "hermanos lati- 
Europa deja de ser, en consecuencia, una entidad sufriente para convertirse en la Europa de destacadas obras artísticas, de tradiciones, eventos y establecimientos inmemoriales que merecen la pena apreciarse. Se trata, en suma, de un discurso sobre una Europa -en esencia, occidental- que se sitúa a caballo entre la veneración de la modernidad francesa e inglesa y el culto de unos orígenes culturales que el autor hace remontar, por un lado, a la Grecia clásica y, por otro, a la España de sus ancestros (cf. Laera 2007: 25).

De modo análogo a la expresión France éternelle, con la que Klengel sintetiza la percepción de ciertos latinoamericanos ante la Francia posbélica (cf. Klengel 2011: 37), puede hablarse, por lo tanto, de una Europa eterna que Mujica Lainez recobra paulatinamente tras el interludio de la guerra. Lo cierto es que París figura ya en noviembre de 1945 como lugar predilecto para "la próxima batalla de ideas" (PF: 96). Las vidrieras de la capital francesa son declaradas "las más bellas y tentadoras del mundo" (AV: 173) y el palacio de justicia de Ruan, "uno de los edificios más hermosos" (AV: 187). De igual manera, en Estrasburgo, el escritor viajero descubre en el museo de L'Euvre Notre-Dame "una de las instituciones más singulares del viejo continente”, además de encontrarse con "uno de los especialistas más sabios de Europa” (PF: 113), i. e. con el historiador del arte y conservador Hans Haug.

El estilo superlativo, así como la mirada idealizadora, que se manifiestan en los pocos ejemplos de 1945, también salpican esporádicamente las crónicas de 1948. En ese viaje corto a Inglaterra, Mujica Lainez no solo dice hospedarse en "uno de los [hoteles] más confortables de Europa” (PF: 138) con referencia al hotel londinense de Gleneagles, sino también observa "la atmósfera de preguerra" -considerada acogedora, por lo menos, para el viajero- que el "turista argentino" (PF: 141) percibe en el Reino Unido, dando a entender que la industria turística ha logrado eliminar, aunque sea en apariencia, las incomodidades de la Europa posbélica. Con vistas a la situación del pueblo británico, el escritor viajero reconoce, sin embargo, vivir "uno de los momentos más contradictorios de todos los tiempos", en el cual las paulatinas mejoras y el subsiguiente "panorama sonriente" (AV: 209) apenas disimulan la precariedad de las viviendas, la falta de electricidad o la escasez alimenticia (cf. AV: 209-210). El año de 1948 conforma, en este sentido, una bisagra entre la inmediata posguerra con la muerte omnipresente, por un lado, y el clima despreocupado de 1958, por el otro. En este tercer viaje por Europa y, en concreto, por España, Francia, Inglaterra, Grecia, Rumanía e Italia, se afianza, en definitiva, la impresión de que

nos", habitaban "la sal del centro del Viejo Mundo, tierra de canciones y de danzas, de leyendas, apasionada” (PF: 321). 
solo lo mejor (cf. PF: 178), lo más bello (cf. PF: 170), lo más grande (cf. PF: 183), lo más hermoso y elegante (cf. PF: 225), así como lo más antiguo de Europa y, de ahí, lo más venerable (cf. PF: 305) consiguen captar la atención del funcionario y escritor.

Ahora bien, de la evolución de la Europa en ruinas a la Europa eterna da prueba, sobre todo, el contraste entre las emociones de signo mayormente negativo en las crónicas de 1945 y las reacciones positivas de 1958: en el último recorrido, Mujica Lainez asegura, pues, frecuentemente admirarse (cf. PF: 181, 190, 321, 331, 345) o expresa el “asombro" (PF: 313, 326), el “entusiasmo" (PF: 239, 311, 313, 361) y la "fascinación” ante lo visto (PF: 161, 177, 194, 202, 220, $294,301)$. Tal es el caso, verbigracia, cuando recorre "en el secreto de la noche" la ciudad de Rodas y siente la "huella de una poderosa fascinación” (PF: 294) ante el legado arquitectónico de la Orden de San Juan. Asimismo, se refiere al “encanto” (PF: 177, 181, 202, 337, 338) y dice gozar de los espectáculos y encuentros, como de aquel "salón literario" (PF: 347) de la pintora italiana Leda Mastrocinque, celebrado en un garaje en Roma (cf. PF: 349; cf. para otros ejemplos PF: 322, 325). Por último, el escritor habla de las sorpresas (cf. PF: 186, 197, 234, 313) y de la “curiosidad” (PF: 180, 199, 219, 376); en particular, de la suya que le impulsó -durante su estancia en Madrid-, a hacer "malabarismos y hasta pequeños milagros personales" para "no perder nada” (PF: 180).

También la cuidada adjetivación deja pocas dudas sobre la "pasión de la belleza y de lo insólito” de Mujica Lainez (Cruz 1996: 24) que constituye -en su doble vertiente- un hilo conductor en los relatos de 1958. Conforme afirma el propio autor durante su estancia en Creta, sus ojos están "aguzados [...] a discernir lo curioso y lo bello” (PF: 301). Por un lado, se observa, en consecuencia, una predilección unívoca por lo curioso (cf. PF: 154, 224, 247, 252, 258, 287, 296, 311, 325, 349, 358), extraño (cf. PF: 157, 159, 285, 307, 355) y raro (cf. PF: 348), siendo la inclinación por lo desconocido e, incluso, la "excentricidad" uno de los fundamentos tanto de la obra como de la autoimagen que el escritor viajero de gusto aristocrático desea proyectar de sí mismo (cf. Cruz 1996: 96; Laera 2007: 16). Por otro lado, su "mirada estética" -que Cruz extiende al conjunto de la narrativa de Mujica Lainez (cf. Cruz en: Vázquez 1983: 189)- se fija preferentemente en las cosas admirables (cf. PF: 168, 181, 192, 322, 340), alegres (cf. PF: 298, 302, 310, 339, 344), divertidas (cf. PF: 258, 312, 339, 348), encantadoras (cf. PF: 311), graciosas (cf. PF: 310, 340) y maravillosas (cf. PF: 281, 340, 354). Según se deduce de los ejemplos referidos, en 1958 predominan, por lo tanto, emotives de connotación positiva. La busca de un entorno europeo y de unos objetos culturales -i. e., sobre todo, arquitectónicos y artísticos- emocionantes permite vislumbrar, al mismo tiempo, un exotismo cultural tanto de signo positivo como de arraigo latinoamericano que no afecta, en primer término, a la 
percepción estereotipada del otro que apenas se presencia en las crónicas. Pero sí evidencia, a través de las descripciones del entorno, una "literatura [...] del status quo" (Aira 1993: 79), ${ }^{14}$ con la cual el embajador cultural Mujica Lainez prosigue la tradición literaria del llamado “viaje a Europa” (Jitrik 1969: 12).

Desde la misma tradición, durante mucho tiempo privativa de las élites adineradas, así como desde "una concepción conservadora que iguala la 'aristocracia de sangre' [...] al refinamiento” (Victory 2017: 345), parece que el cronista pretende distinguirse, a la vez, de las masas turísticas que se hacen notar, con vigor, en el viaje de 1958. Discerniendo al turista Baedeker como antimodelo, Peñate Rivero ve en el turismo, justamente, uno de los fenómenos más criticados por Mujica Lainez (cf. Peñate Rivero 2012: 292), sobre el cual el escritor se explaya tanto en una crónica del 20 de junio de 1948, escrita desde Londres, como en dos textos redactados en Venecia y Roma en mayo y junio de 1958, respectivamente (cf. PF: 141-145, 328-336, 362-370). Es verdad que el turismo parece perturbar la armonía de su viaje europeo. Con alusión al título Placeres y fatigas de los viajes, es la fatiga entre los placeres que descubre. Así pues, el propio Mujica Lainez confirma la "aparente acritud escéptica” en sus observaciones y menciona la incomodidad que le provocan sus "hermanos andariegos" (PF: 335). En otras ocasiones, se mofa hasta abiertamente del viajero “inocente y elemental” (PF: 364) y de sus excesos absurdos; o destaca, de modo sarcástico, que "[l]o importante es que el turista sea feliz; que envíe cientos de postales; que adquiera esas miniaturas que venden en los museos" (PF: 334). Con esta actitud, el escritor no solo parece dar continuidad a la "retórica del antiturismo” emergida con la propia aparición del fenómeno turís-

14 El escritor argentino César Aira distingue tres tipos de exotismo: con referencia a las Cartas persas, la célebre novela epistolar de Montesquieu, el primer tipo de exotismo es el que se desprende del relato de un persa en París, tal y como lo plantea el autor francés con el objetivo de aproximarse críticamente a su propia realidad. El segundo exotismo sería el que se encuentra en la historia de un francés en Persia, escrita desde la misma perspectiva gala que se transformaría, por lo tanto, en el punto de vista de un viajero. En el tercer exotismo, un escritor persa descubriría, finalmente, una "Persia 'persa"” a los lectores franceses y, con ello, llevaría a cabo una "fetichización de la nacionalidad" (cf. Aira 1993: 74-75). Si bien las crónicas de Mujica Lainez no pertenecen al género ficcional, a partir del cual Aira establece su categorización, ni versan sobre los países exóticos a los que se aluden en el ensayo crítico -Persia, África, América, Tahití o China (cf. Aira 1993: 74)-, las mismas encajan en la definición del segundo tipo de exotismo: por un lado, porque estas reflejan la perspectiva de un viajero, pero, por otro lado, también por la comercialización de la imagen del otro europeo que recogen y el riesgo inherente de caer en la superficialidad o frivolidad del "exotista" que "se limita a reconocer lo que ve, que es lo [que] ya ha visto, lo que ya sabe, y nada más" (Aira 1993: 78; cf. también Aira 1993: 75-76). 
tico (Pagni 2010: 47), sino también se descubre como integrante de una clase argentina en "decadencia y desaparición ineludibles" -aquel de los "hijos y nietos de la aristocracia” (Victory 2017: 343)-, que lamenta la pérdida de la exclusividad viajera.

No obstante, ha de anotarse que Mujica Lainez, al insistir en la apariencia de su acritud (cf. PF: 335), es, a la vez, plenamente consciente de las contradicciones e incluso de la hipocresía inherente a su postura, aunque eso no parece incomodarle excesivamente. Omitiendo ante los lectores el hecho de estar en un viaje de negocios, él mismo se presenta, al fin y al cabo, como turista común. “¿Qué soy sino uno de los tantos turistas, que van y vienen preguntando y anotando?” (PF: 335), interroga, y termina admitiendo que "los detesto por todo lo que encuentro en ellos parecidos a mí” (PF: 336). Se trata, por lo tanto, de un amor-odio que le sirve como argumento tanto para seguir criticando como para defender la utilidad de los viajes, de los que él mismo es partícipe.

En relación con la equiparación inicial del acto de viajar con el de aprender, esta defensa de índole utilitarista ofrece un giro inesperado. Si en la definición de 1945 aprender es, sobre todo, observar e investigar (prevaleciendo la información sobre la emoción), ahora las emociones conforman la vía predilecta y hasta la más democrática del conocimiento, habida cuenta de que dejan huellas “aun en el cerebro más tupido” (PF: 335):

El turismo es, dejando aparte sus absurdos, una actividad provechosísima, porque siempre, aun en el cerebro más tupido [...], deja algo útil, algo que es, por lo menos, como una inquietud, como una incitación al progreso [...]. Porque siempre queda algo -emociones, sugestiones, deslumbramientos- como fruto de un viaje, algo más que noticias sobre precios de albergues, líneas de ferrocarriles, comidas típicas y el disgusto de no disponer del acostumbrado "breakfast". Algo... (PF: 335)

De este modo, Mujica Lainez comparte, por lo tanto, las emociones del turista, en cuanto valor añadido a la mera información. Aun así, no puede dejar de advertir, desde cierta posición de superioridad, que sus sentimientos y conocimientos -ambos, cultos y refinados- no se alcanzan con el turismo rápido y masivo que intenta en poco tiempo impregnarse de un máximo de conocimiento. A su juicio, la rapidez impide, en definitiva, interiorizar lo aprendido, con el nefasto resultado de que la felicidad y la "paz turística” (PF: 369) se disipan, transformándose en una angustiosa búsqueda de la información volatilizada. 


\section{Conclusiones}

Las crónicas de viajes de Manuel Mujica Lainez, redactadas en 1945, 1948 y 1958, no solo se inscriben en la larga tradición latinoamericana del viaje a Europa, sino también contribuyen a un discurso global, dinámico y multidireccional sobre un continente que en 1945 empieza a levantarse de sus escombros. El examen de los enunciados emocionales en dicho contexto histórico ha evidenciado un desarrollo a lo largo de los tres viajes y corroborado la discontinuidad emocional y la influencia del contexto, de la memoria, así como de las convenciones ético-morales en el dispositivo emocional. A nivel metodológico, el análisis de los emotives se ha complementado con el examen de la retórica de la emoción, lo cual ha permitido llamar la atención sobre Mujica Lainez en cuanto emisor de los enunciados emocionales o, dicho de otra manera, sobre la función emotiva o expresiva de la comunicación literaria, pero también sobre la relevancia de los receptores (es decir, de la función apelativa o conativa de la comunicación literaria) a la hora de examinar las emociones expresadas en las crónicas de viajes. De este modo, la transformación del cronista y periodista de 1945 al viajero de 1958 se ha visto reflejada, en primer lugar, en un desarrollo de las emociones mayormente negativas en el primer viaje -aun cuando el término genérico "emoción” y su verbo "emocionarse” cobren un significado positivo- a las emociones mayormente positivas en el último. Al mismo tiempo, el “clima guerrero", mediante el cual Mujica Lainez compendia las emociones que siente ante la Europa en ruinas, se refuerza con una serie de recursos retóricos -isotopías, adjetivos, superlativos, metáforas, exclamaciones, personificaciones e, incluso, el topos de lo indecible- que generan un contraste unívoco con las despreocupadas andanzas de 1958. En las crónicas de este último año, se observa, en cambio, una idealización y una descontextualización referente a la actualidad política y social de Europa, la cual se convierte, por esta vía, en una Europa eterna, en la que el placer y, en particular, la búsqueda de lo curioso y lo bello prevalecen sobre las pocas fatigas que Mujica Lainez asocia, por ejemplo, con el turismo de masas. Las dicotomías resaltadas con respecto al desarrollo de Europa y de las emociones que el continente suscita se reafirman, por último, en la percepción utilitarista del propio viaje. Mientras que la utilidad del viaje y de su relato radicaban, en 1945, en el valor informativo, la misma consigna del "viajar aprendiendo" acentúa en 1958 el beneficio de las emociones que dejan huellas, en palabras de un Mujica Lainez altivo, "en el cerebro más tupido" (PF: 335). Esta alteración en la definición del aprendizaje rompe, por lo tanto, con la tradicional polaridad entre razón y emoción, proponiendo, en definitiva, desde la perspectiva del escritor viajero una tercera vía, en la que ambos polos se conjugan. 


\section{Bibliografía}

Aira, César (1993): “Exotismo”. En: Boletín del Grupo de Estudios de Teoría Literaria 3, pp. 73-79.

Bartra, Roger (2012): “La batalla de las ideas y las emociones”. En: Moraña, Mabel / Sánchez Prado, Ignacio M. (eds.): El lenguaje de las emociones: Afecto y cultura en América Latina. Madrid / Frankfurt a. M.: Iberoamericana / Vervuert, pp. 17-36.

Benda, Julien et al. (1947): L'esprit européen. Rencontres internationales de Genève / 1. Neuchâtel: Ed. de la Baconnière. <http://palimpsestes.fr/textes_philo/jaspers/rencontres. pdf> (21/09/2019).

Boccagni, Paolo / Baldassar, Loretta (2015): “Emotions on the Move: Mapping the Emergent Field of Emotion and Migration”. En: Emotion, Space and Society 16, pp. 73-80.

Clément, Maéva / Sangar, Eric (2018): “Introduction: Methodological Challenges and Opportunities for the Study of Emotions”. En: Clément, Maéva / Sangar, Eric (eds.): Researching Emotions in International Relations. Cham: Palgrave Macmillan, pp. 1-28.

Cruz, Jorge (1996) [1978]: Genio y Figura de Manuel Mujica Lainez. Buenos Aires: Editorial Universitaria.

Cruz, Jorge (1982): “Manuel Mujica Lainez”. En: Zanetti, Susana (ed.): Historia de la literatura argentina 5. Los contemporáneos. Buenos Aires: Centro Editor de América Latina, pp. 73-96.

Doering, Detmar / Koch-Mehrin, Silvana (2009): Für ein Europa der Freiheit: Beiträge zur Verfassungsordnung der europäischen Union. Berlin: Liberal Verlag.

Du Réau, Élisabeth (2001): L'idée d'Europe au XXe siècle: Des mythes aux réalités. Bruxelles: Éd. Complexe.

Flash Eurobarometer (2019): Emotions and Political Engagement towards the EU. <https:// www.europarl.europa.eu/at-your-service/files/be-heard/eurobarometer/2019/emotionsand-political-engagement-towards-the-eu/report/en-flash-2019.pdf> (25/10/2019).

Geisenhanslüke, Achim (2018): Poetik: Eine literaturtheoretische Einführung. Bielefeld: Transcript.

Gerner, Martin (2012): "Back to the Roots - Emotionalising Europe”. En: Pinheiro, Teresa / Cieszynska, Beata / Franco, José Eduardo (eds.): Ideas of / for Europe. An Interdisciplinary Approach to European Identity. Frankfurt a. M. et al.: Peter Lang, pp. 651-661.

Hochschild, Arlie Russell (1979): “Emotion Work, Feeling Rules, and Social Structure”. En: American Journal of Sociology 85.3, pp. 551-575.

Jitrik, Noé (1969): “Crónicas del viaje a Europa”. En: Jitrik, Noé (ed.): Los argentinos IX: LoS viajeros. Buenos Aires: Editorial Jorge Álvarez, pp. 11-20.

Klengel, Susanne (2011): Die Rückeroberung der Kultur: Lateinamerikanische Intellektuelle und das Europa der Nachkriegsjahre (1945-1952). Würzburg: Königshausen \& Neumann.

Laera, Alejandra (2007): “Un hombre de mundo”. En: Mujica Lainez, Manuel: El arte de viajar. Antología de crónicas periodísticas (1935-1977). Ed. Alejandra Laera. Buenos Aires et al.: Fondo de Cultura Económica, pp. 11-39.

Mujica Lainez, Manuel (1984) [1983]: Placeres y fatigas de los viajes (Crónicas andariegas I). Buenos Aires: Editorial Sudamericana.

Mujica Lainez, Manuel (2007): El arte de viajar. Antología de crónicas periodísticas (1935-1977). Ed. Alejandra Laera. Buenos Aires et al.: Fondo de Cultura Económica. 
Pagni, Andrea (2010): "Ser o no ser turista. Relatos de viajes a Europa". En: Laera, Alejandra (ed.): Historia crítica de la literatura argentina. Buenos Aires: Emecé, pp. 39-60.

Peñate Rivero, Julio (2004): “Camino del viaje hacia la literatura”. En: Peñate Rivero, Julio (ed.): Relato de viaje y literaturas hispánicas. Madrid: Visor Libros, pp. 13-29.

Peñate Rivero, Julio (2012): Introducción al relato de viaje hispánico del siglo XX: textos, etapas, metodología (I: 1898-1980). Madrid: Visor Libros.

Reddy, William M. (1999): “Emotional Liberty: Politics and History in the Anthropology of Emotions”. En: Cultural Anthropology 14.2, pp. 256-288.

Sanchez Salgado, Rosa (2018): “The Advocacy of Feelings: Emotions in EU-Based Civil Society Organizations' Strategies”. En: Politics and Governance 6.4, pp. 103-114.

Siguan, Marisa (2014): Schreiben an den Grenzen der Sprache: Studien zu Améry, Kertész, Semprún, Schalamow, Herta Müller und Aub. Berlin: De Gruyter.

Stets, Jan E. (2010): “Future Directions in the Sociology of Emotions”. En: Emotion Review 2.3, pp. 265-268.

Stets, Jan E. / Trettevik, Ryan (2014): “Emotions in Identity Theory”. En: Stets, Jan E. / Turner, Jonathan H. (eds.): Handbook of the Sociology of Emotions: Volume II. Dordrecht et al.: Springer, pp. 33-49.

Svašek, Maruška (2012): “Emotions and Human Mobility: Key Concerns”. En: Svašek, Maruška (ed.): Emotions and Human Mobility: Ethnographies of Movement. London / New York: Routledge, pp. 1-16.

Vázquez, María Esther (1983): El mundo de Manuel Mujica Lainez. Buenos Aires: Editorial de Belgrano.

Victory, Solange (2017): “Cronistas de la casa en decadencia: Lúcio Cardoso / Manuel Mujica Láinez". En: Croce, Marcela (ed.): Historia comparada de las literaturas argentina y brasileña. De la vanguardia a la caída de los gobiernos populistas (1922-1955). Córdoba: Editorial Universitaria Villa María, pp. 341-357.

Villena, Luis Antonio de (1976): Antología general e introducción a la obra de Manuel Mujica Lainez. Madrid: Felmar. 